\title{
Position Statement: Sustainable Information and Information Systems (SIIS)
}

\author{
Duane Truex, Leif Olsson, Katarina Lindblad-Gidlund, Johanna Sefyrin, \\ Aron Larsson, Olof Nilsson, Karen Anderson, Erik Borglund, and Viveca Asproth \\ Department of Information Technology and Media, Mid Sweden University \\ Tel.: +46 (0) 771-975000 \\ katarina.lindblad-gidlund@miun.se
}

\begin{abstract}
In this position statement we provide our understanding of the relation between the IS field and the notion of sustainability, and present our focus through a characterization of the "sustainability research" construct. By doing so, we hope to contribute to the discourse on a clarification of the construct itself in our research community.
\end{abstract}

Keywords: information, information systems, sustainability, economical, ecological and social dimensions.

\section{Introduction}

The three-fold purpose of this position statement is to first provide a space within which we conceptualize the relation between the IS field and the notion of sustainability. Second, the statement aims at presenting the focus of a community of scholars at a mid-sized Scandinavian university; our current work is collectively characterized as falling under the umbrella notion of "sustainable information and information systems" (SIIS). Thirdly, through the description of this group's characterization of the "sustainability research" construct, to contribute to a clarification of the construct itself in the IS research community.

We are well aware of the definitional disputes around the meaning of "sustainability" and, as Poet Mark vanTiblurg reminds, "In naming meaning begins", that a robust debate about the meaning(s) of the term is essential in developing standards, metrics and acceptable approaches to researching the topic. There exist a wealth of literature reviews and other articles that elaborate the definition of sustainability and describe a range of projects falling in the domain of sustainability research. We do not aim to replicate that work but rather summarize key threads that have helped establish the boundaries of our own definition, one that guides our inter and multi disciplinary inquiries currently in the early stages of development. We share that definition below.

\subsection{Sketching the Field of Sustainability}

In the Brundtland report (Our Common Future, 1987) sustainable development is defined as: "Sustainable development is development that meets the needs of the 
present without compromising the ability of future generations to meet their own needs". However, sustainability is usually divided into three interdependent dimensions: 1) economic, 2) environmental and 3) social sustainability (e.g. McKenzie, 2004). In the realm of economic sustainability we concur with Daly (1990, 1991) who discusses growth versus development, and underscores that while " "growth" refers to expansion in the scale of the physical dimensions of the economic system ... "development" refers to qualitative change of a physically nongrowing system in a state of dynamic equilibrium maintained by its environment" (1990, p. 33). Daly's conclusion is that sustainable economic development is a better term than sustainable economic growth. With regards to environmental sustainability we find Williams' and Millington's (2004, p. 101) distinction between weak and strong sustainability helpful in anchoring ends of a continuum; i.e., strong- as the expansion of the stock of resources in order to meet the increasing demands, vs. weak-a focus on revision of these demands. The basic problem with this continuum is the so-called 'environmental paradox', referring to the "mismatch between what is demanded of the Earth, and what the Earth is capable of supplying" (Williams \& Millington, 2004). Finally, in relation to social sustainability McKenzie (2004, p. 18) writes that: "Social sustainability occurs when the formal and informal processes, systems, structures and relationships actively support the capacity of current and future generations to create healthy and livable communities. Socially sustainable communities are equitable, diverse, connected and democratic and provide a good quality of life". Based on McKenzie (2004) we view social sustainability as a locally situated condition and a process.

\subsection{Sustainability in Relation to Information and Information Technologies Systems}

It is hardly possible to address the concept of sustainability and avoid the notion of technologies since technologies often are either expected to solve many of the problems and tensions linked with a sustainable future or are viewed as part of the source that creates them (Daly, 1990, 1991; Williams \& Millington, 2004; McDermott \& Hagemann, 2010). Irrespective of perspective, reflections on the intersection of sustainability and technologies demand theoretically well-founded analyses and close empirical studies in order to create valuable knowledge on how they interact. On a general level, analyses of how technologies and societal development interrelate are to be found in several reference disciplines of IS such as Sociology of Technology (Berg, 1998), Science and Technology Studies (1998), and Philosophy of Technology (Feenberg, 1999). Sustainability in specific is however a more scarcely treated concept even though it has gained in attention lately (see for example Mihelcic et al, 2003 for engineering and Mitrea et al, 2010 for ICT construction). An exception is though the linkage between information systems and sustainable competitive advantage (Clemens, 1986) and economic growth (Avgerou, 2003) that has played a more prominent part. Thus, as indicated by the choice of definitions above we would like to propose a slightly different pathway. 


\section{Our Points of Departure}

As a starting point in our work we interpret sustainability to refer to a complex and multidimensional ontological space addressing economic, ecological and social / societal concerns. Situated in a Swedish context that presumes democratic participation and commitment to social justice and societal equality, our preliminary conception of sustainability pays attention to unequal power relations and injustices, prefers development rather than growth, and the reuse of existing resources rather than finding or exploiting new extractive resources. In our view a robust concept of sustainability is defined locally and is not scalable from the local, regional or global domains. Finally, we concur with McKenzie's argument that sustainability is not only a condition but also a process in which participation and democracy are central.

\subsection{Our Approaches to the Field}

In the Mittuniversitetet SIIS group three different research approaches to Information and Information systems are united:

- The ValIT (Value creation with IT) group focuses on how value is translated, enacted and performed in IT-related processes.

- The CEDIF group brings together professional and research expertise in: a) Recordkeeping (archives and records management) b) Business process analysis c) Systems design d) Information architecture e) Long-term digital preservation.

- The CRIINFO group focuses on design of systems for accessibility of critical information which is carried out through applied research in close cooperation with stakeholders in order to create benefit.

Within the SIIS solutions-oriented approaches to sustainable information and information technologies coexist with approaches that focus on problematizing the issues related to sustainability and definitions thereof. These approaches are not necessarily based on the same worldviews, definitions of sustainability or the same science theoretical points of departure, and this sometimes causes tensions. However, we view of these tensions and differences as productive in that they give rise to new questions and understandings of the issues at hand.

\subsection{Preliminary Research Questions}

A general aim is to explore how IT is used in efforts to develop a more sustainable society. We have four preliminary research questions:

- How are information technologies present / involved / active in the doing of transition processes to a more sustainable society; how do they hold unforeseen potential, and how may they make visible activities outside of the established?

We also examine how investments in infrastructure and new technologies can be evaluated regarding uncertain profitability as well as how their contribution to the three dimensions of sustainable development can be aided by computer based decision support. Of particular interest is the employment of societal decision analysis 
together with methods for valuation of investment decisions under uncertainty. This drive two further research questions are:

- How is it possible to use information technologies in order to promote infrastructure investments, for instance, investments in renewable energy as part of the transition towards sustainability?

- How are information technologies involved in various solutions believed to lead to a more sustainable development?

- Finally we investigate the design and develop IT solutions in support of an effective management of the transition process by asking:

- How may information technologies be utilized when developing towards a more sustainable development, in terms of IT-design solutions?

\section{Conclusions}

In conclusion, by first providing our understanding of the relation between the IS field and the notion of sustainability, and second presenting our focus through a characterization of the 'sustainability research' construct, we hope to contribute to a clarification of the construct itself in our research community.

\section{References}

Agyeman, J.: Where justice and sustainability meet. Environment 47(6), 10-23 (2005)

Avgerou, C.: The link between ICT and economic growth in the discourse of development. In: Korpela, M., Montealegre, R., Poulymenakou, A. (eds.) Organizational Information Systems in the Context of Globalization. Kluwer Academic Publishers, Boston (2003)

Berg, M.: The Politics of Technology: On Bringing Social Theory into Technological Design. Science, Technology, \& Human Values 23(4), 456-490 (1998)

Daly, H.E.: Sustainable development: from concept and theory to operational principles. Population and Development Review 16, 25-43 (1990)

Daly, H.E.: Operational principles for sustainable development. Earth Ethics (1991)

Feenberg, A.: Questioning Technology. Routledge, New York (1999)

McDermott, B., Snabe, J.H.: 2010 Sustainability Report 4 (2010),

http: / /www. sapsustainabilityreport.com 